\title{
Basic Procedures and Methodological Support of the «Object-Based Environment for Engineering Calculation in the MATLAB System» Course
}

\author{
Stanislav A. Lyushnin ${ }^{1 *}$ \\ ${ }^{1}$ Bauman Moscow State Technical University, 2nd Baumanskaya str., 5/1, 105005, Moscow, Russia
}

\begin{abstract}
This paper looks at methodological aspects of the «Objectbased environment for engineering calculation in the MATLAB system» course offered to the second year students of Bauman Moscow State Technical University for mastering tools in the MATLAB environment, learning MATLAB language and object-oriented technology of working with classes and applications, designed for engineering calculations of ammunition characteristics. The paper presents the technology of organization of practical studies using resources of MATLAB Grader.
\end{abstract}

\section{Introduction}

Training of the new generation of research engineers ready to become leaders in high technology industrial sectors requires an innovative approach to organization of learning environment. Starting from the early noughties scientists of the «High-precision aircraft» division actively study and develop two types of information technologies for development of ammunition and means of destruction: using numerical modelling packages for detailed study of physical processes (for example, ANSYS AUTODYN or LS-DYNA) [1-5] and software packages for mathematical modelling which systemically link the entire learning process (for example, MATLAB) [6-10, 16]. The «Object-based environment for engineering calculation in the MATLAB system» course was developed by SM4 «Highprecision aircraft» division in accordance with Self-imposed BMSTU educational standard, the basic professional educational program for students majoring in «Ammunition and fuses». The aim of studying the discipline is to master tools in the MATLAB environment, learn MATLAB language and object-oriented technology of working with classes and applications, designed for engineering calculations of ammunition characteristics [10-14]. Later on these skills and knowledge are used in the following courses: "Information technologies in design engineering», «Computer-aided engineering systems of means of destruction», «Munitions effectiveness», «Object based methods of evaluation of munitions effectiveness», «High-precision munitions guidance and control systems».

* Corresponding author: lushnin@bmstu.ru 


\section{Main Text}

Educational learning material for the «Object-based environment for engineering calculation in the MATLAB system» course include:

- lectures and additional self-instructional material (electronic versions are distributed among students at the start of the semester);

- tasks for practicals (handed out in electronic form ahead of each session; also developed are online versions of certain tasks using resources of MATLAB Grader);

- homework (handed out to students in the middle of the semester);

- developed software.

The series of lectures looks at the following problems:

1. Basic definitions. Intended use of MATLAB system. Visual environment and user interface. Interactive mode of operation. Working with the command prompt.

2. Window customization, fonts, current directory. Help system and other subsystems of MATLAB. Editor and M-files. Types of M-files (scenarios and functions). Typing and saving texts. Commentaries. Saving data from the work area. Data types. Arithmetic operations with numbers. Logical operations, relation operations. Standard functions. Character arrays and char data type. Basic computations. Working with matrices and vectors. Colon and multiple indexing. Multidimensional matrices.

3. Data visualization. Plot command. Bar graphs and histograms. Two-dimensional charts. Stepped curve. Plotting graphs in polar coordinates. Curves with tolerances. Representation of functions. Three-dimensional graphs. One-dimensional curve in space. Mesh surfaces. Isolines. Vector fields. Creating animated images. Controlling animated images.

4. Debugging, breakpoints, step-by-step execution. Cycles and conditional statements (for, while, if, case). Defining and calling of functions. Scope of variables. Interactive input and output of messages. Creating graphic interfaces (GUI) in MATLAB. GUI development environment GUIDE. GUI application components. Graphic object properties. Events and responses to events. Tools for developing standalone applications.

5. Symbolic calculations. Computations using arbitrary-precision arithmetic. Simplification of expressions functions - simplify, simple. Expanding of expressions function - expand. Factoring expressions - factor function. Reduction of similar terms - collect function. Substitutions - subs function. Function calculating limits - limit. Derivative computation function - diff. Integral computation function - int. Taylor series expansion function - taylor. Series sum calculation function - symsum. Solving algebraic equations and systems - solve function. Solving differential equations dsolve function. Plotting functions - ezplot, ezpolar commands.

6. Visual representation of the optimization task. Starting optimization using the Optimization Toolbox. Setting objective functions. Types of restrictions. Definition of linear constraints. Boundaries and general linear inequalities. Linear equations. Definition of nonlinear constraints. Choice of solver and options. Parameters and optimization settings. Limitations of the Optimization Toolbox algorithms. Global Optimization Toolbox algorithms. Genetic algorithms.

7. The basic principles of object-oriented programming technology. Classification of domain objects. Designing a class hierarchy. Features of programming classes in MATLAB. Constructors. Class inheritance. Overlapping classes. Overlapping operations. Examples of overlapping arithmetic operations in MATLAB classes and custom classes.

8. Designing a class hierarchy of geometric objects for modeling aggregate target models, discrete fields of flying fragments and areal objects. Class methods of flat objects. 
The class of polygons as universal objects for planar figures. Virtual methods of classes of plane figures. The hierarchy of classes of three-dimensional objects. The class of polyhedra as universal objects for three-dimensional objects. Virtual methods of classes of threedimensional bodies based on the example of methods of textual and graphical visualization of objects display and Show.

9. Point class: structure, constructor, class methods, virtual methods. Shape class: structure, constructor, class methods, virtual methods. Classes of polygons (PolyRect), rectangles (Rect) and circles ( $\mathrm{Cir}$ ). Shape 3 class: structure, constructor, class methods, virtual methods. Parashape and Cylshape classes. Polygran class: universal operations with three-dimensional objects in Polygran class methods. Projections of polyhedra. Visualization of polyhedra.

10. Programming methods for determining points in flat figures. Combining of flat shapes. Intersection of flat shapes. The total area of overlapping shapes. Fuzzy figures, membership functions. Classes of fuzzy figures. Intersections of flat fuzzy shapes. Fuzzy overlap area of multiple overlapping fuzzy shapes.

11. Gaussian distribution. Class of normally distributed random variables Norm_1. Methods of the class Norm_1. Integral operations in the class Norm_1. Two-dimensional normal distribution. Two-dimensional normal distribution parameters. The class of twodimensional normally distributed random vectors Norm_2. Methods of the class Norm_2. Projections of objects Norm_2 into objects of the class Norm_1. Object addition operations Norm_2 with objects Point (distribution center offset). $\overline{\text { Object multiplication }}$ operations Norm_2 on Point objects (scattering characteristics scaling). Random vector addition operations.

12. The probability of a point falling within the interval. Ver method for calculating the probabilities of falling within the interval. The probability of a point falling within a rectangle. Probability of falling within a scattering ellipse. Ver method in the Norm_2 class and calculation of the probabilities of getting within a rectangle and a scattering ellipse. Sets of figures as arguments to the Ver method in the class Norm_2. The probability of getting within a small figure of arbitrary shape. Generalization of the method for calculating the probabilities of a point falling within a plane figure over the class of polygons. Calculation of the probability of getting within polyhedron projection elements by the Ver method. Generation of random points in the Norm_2 class. Statistical modelling of the normal distribution on the plane using the methods of the Norm 2 class.

Structured e-lectures contain lots of examples of both classic math problems and problems specific for this university chair:

- greater attention devoted to mastering technologies for analysis of experimental data;

- presented mathematical models describing dynamics of warfare;

- introduced mathematical models for targeting aerial vehicles;

- special attention paid to optimization method including genetic algorithms;

- object-oriented technologies also viewed in the context of engineering research.

Additional materials for unsupervised activities (customized course of lectures «The theory of probability») look at object-oriented technology of probability calculation for solving different tasks of operations research tied with accidental events' analysis, algebra of random variables and functional relationships between them, systems of random vectors [15]. The materials cover the following problems:

- probabilities of complex events;

- Bayes' formula;

- Bernoulli distribution; 
- discrete random variables;

- base class of continuous random variables;

- exponent rule and distribution classes tied with it;

- normal law of distribution;

- class of two-dimensional normally distributed vectors;

- functions of random variable;

- multiplicative functions of random variable;

- additive functions of random variable.

Software for individual use by students is published at the GitHub website (https://github.com/ETMC-Exponenta/ProbabilityAnalysis-M4/) and compiled into separate binary package. This library uses electronic formula technology [16]. Those formulas are syntactically built in the MATLAB work area as function calls having substantive interpretation in the theory of probability context. They perform actions depending on the combination of arguments. For example, if $\mathrm{X}$ is a random variable with a known law of distribution, $G$ is a geometric shape or an array of non overlapping shapes, then the electronic formula $[\mathrm{P}, \mathrm{P}]=\operatorname{Ver}(\mathrm{X}, \mathrm{G})$ computes probability $\mathrm{P}$ of the random variable $\mathrm{X}$ assuming a value within an interval $\mathrm{G}$. Object $\mathrm{X}$ is created by a constructor of one of the random variable classes with the corresponding parameters, for example, $\mathrm{X}=$ Norm 2 $([1 ; 2],[3,2], 0.5)$ is a normal distribution on the plane object with mathematical expectations along coordinates equal to 1 and 2, mean-square deviation of 3 and 2 , correlation coefficient between coordinates of 0.5 . G object can be created by a constructor of circles with a given radius, centered in a certain point, $G=\operatorname{CirC}(2$, $[0 ; 2])$, rectangles $G=\operatorname{Rect}([5,3])$ or other shapes, may be also with the result of joining of overlapping of shapes (Fig. 1):
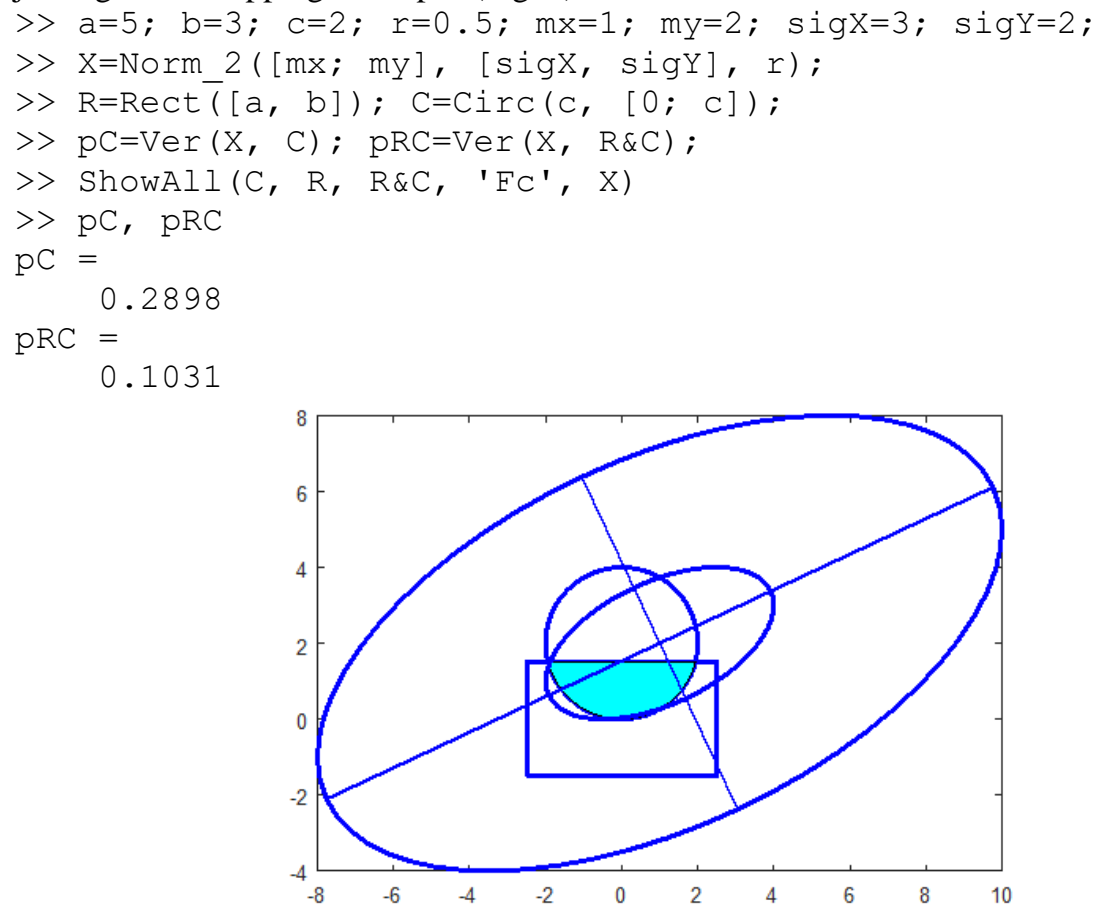

Fig. 1. Representation of operations on shape objects and computations of probability of the variable assuming a value within a given interval. 
Results of computing electronic formula Ver depends on the structure of the object G. If $G$ is an array of shapes, $P$ is a probability of hitting at least one of them, $p$ is an array of probabilities of hitting individual shapes. So, computing of the probability of hitting, for example, an ellipsoid using the universal electronic formula Ver is easier than using the special formula FLaplas based on tables of Laplace Transforms:

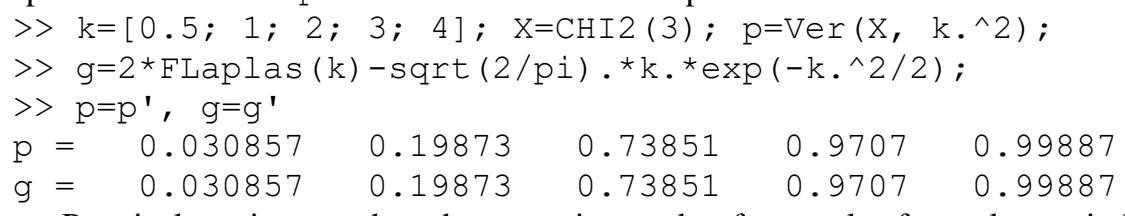

0.9707

0.99887

Practical sessions are based on creative study of examples from electronic lectures and suggest using math modelling software package MATLAB (it is possible to use both a local version and an online version available at https://matlab.mathworks.com/ (Fig. 2)).

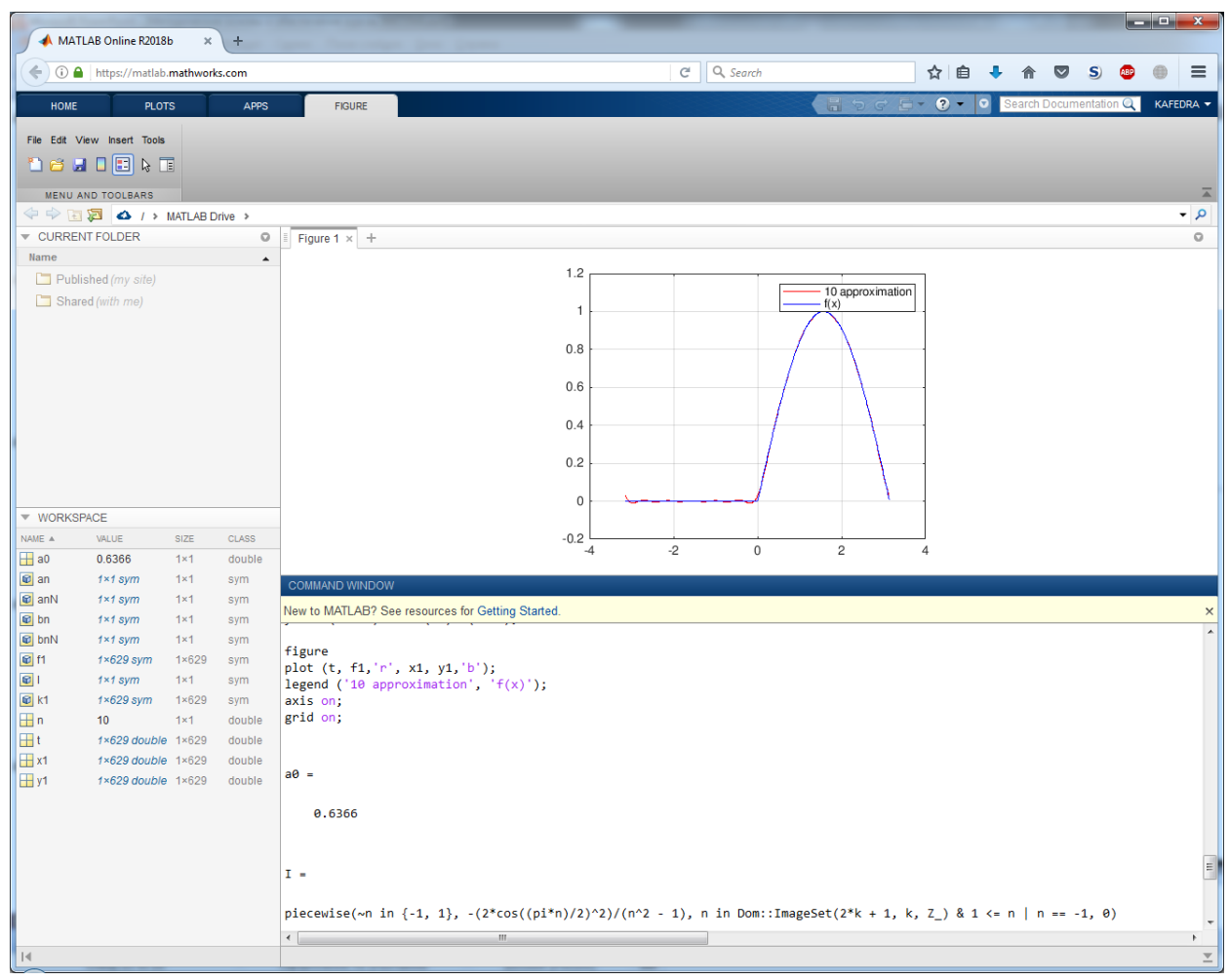

Fig. 2. Approximation of the function graph in online version of MATLAB.

Practical sessions suggest acquiring and consolidating of the following skills:

- working with matrices and vectors in MATLAB;

- building two-dimensional, three-dimensional and special graphs of functions;

- programming in MATLAB environment;

- solving systems of algebraic and differential equations;

- solving optimization problems in MATLAB;

- studying classes Point, Shape, Rect, Cir. Studying classes of threedimensional geometric objects. Studying methods of intersection of flat shapes. Solving flat 
shapes intersection problems using geometric object class methods in MATLAB environment;

- studying methods of two-dimensional normally distributed random vectors class, computing probability of random points to assume positions inside flat shapes using methods of class Norm_2;

- studying statistical methods for evaluation of frequency of values assuming positions inside flat shapes. Determining of possibilities for random points assuming positions inside areas of random configuration. Solving problems of statistical modelling using classes of geometric objects and random normally distributed vectors inside MATLAB environment.

Practical sessions based on additional materials offer self-instructional interactive learning to use online (or offline) version of MATLAB or the developed software. Adapted lecture course «The theory of probability» contains verified examples of problem-solving which can be copied into the MATLAB environment (the developed software). The solution can be obtained, text or graphic results visually compared with those in the lectures (Fig. 3) and, using the acquired skills, you can try to solve test problems from the educational materials. Some test problems are published in the online MATLAB Grader environment and are available to authorized students in certain time intervals during the course study (Fig. 4).

The homework is aimed at acquiring object-oriented technology skills for dealing with classes and creating a class for storing information about geometric (mathematical) objects in the MATLAB environment.

Preparing versions of practical problems in the MATLAB Grader environment is performed interactively in several steps (Fig. 5):

- problem stating (it is possible to visually represent mathematical dependencies inside the text of the problem using LaTeX language);

- creating model solution in MATLAB language, hidden from the student;

- creating a template for the student in MATLAB language (when creating the template, the aim is also to link the developed library with functions which can be used for solving the problem);

- determining solution verification criteria: using keywords and comparing the results obtained with benchmark values;

- testing of the solution (it is possible to output graphic materials).

Authorized access to online problems is performed by sending invitations through email. The course administrator totally controls the process of solving and correctness of the results obtained during manual and automatic analysis of CSV and Microsoft Excel pivot tables or text M-files (Fig. 6). It seems, the most optimal way of creating such problems is a preliminary preparation of materials in a text file because all tasks use textual notation of MATLAB language. 


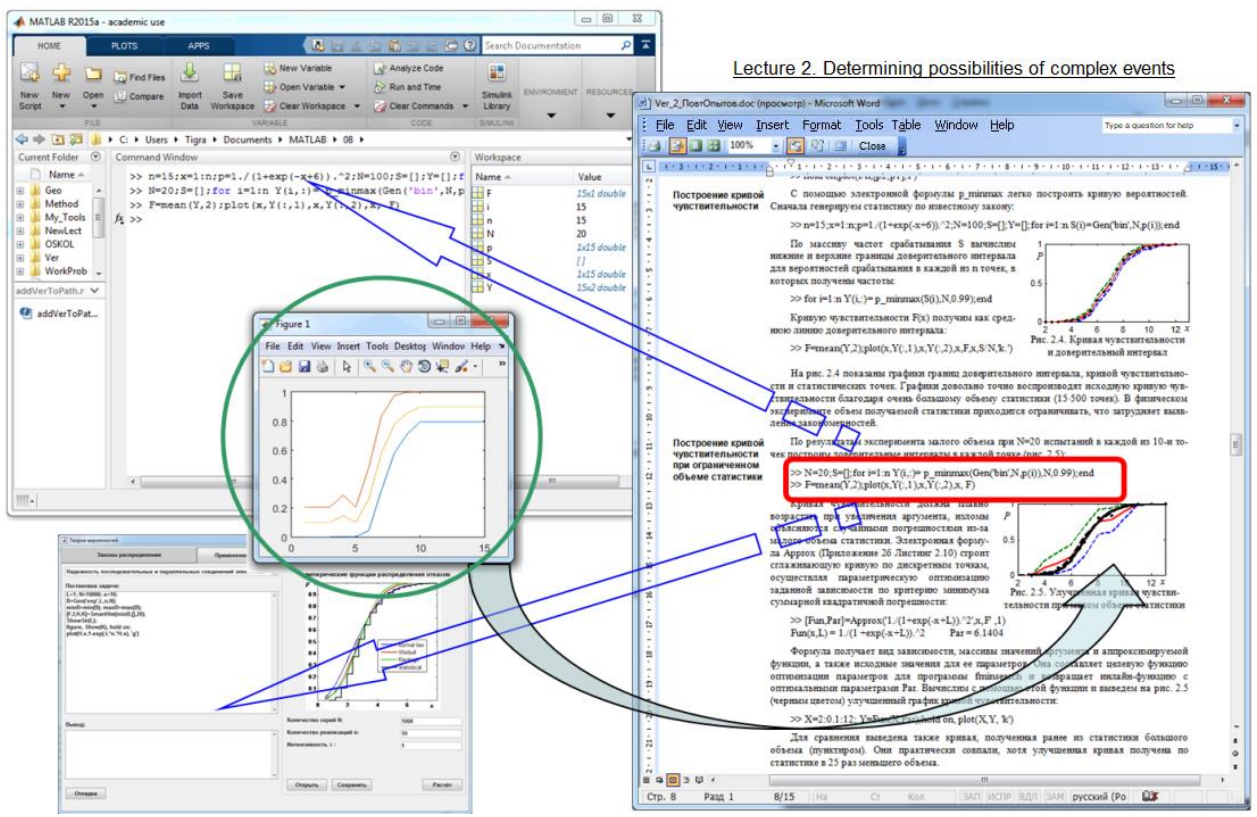

Fig. 3. Interactive study of lectures.

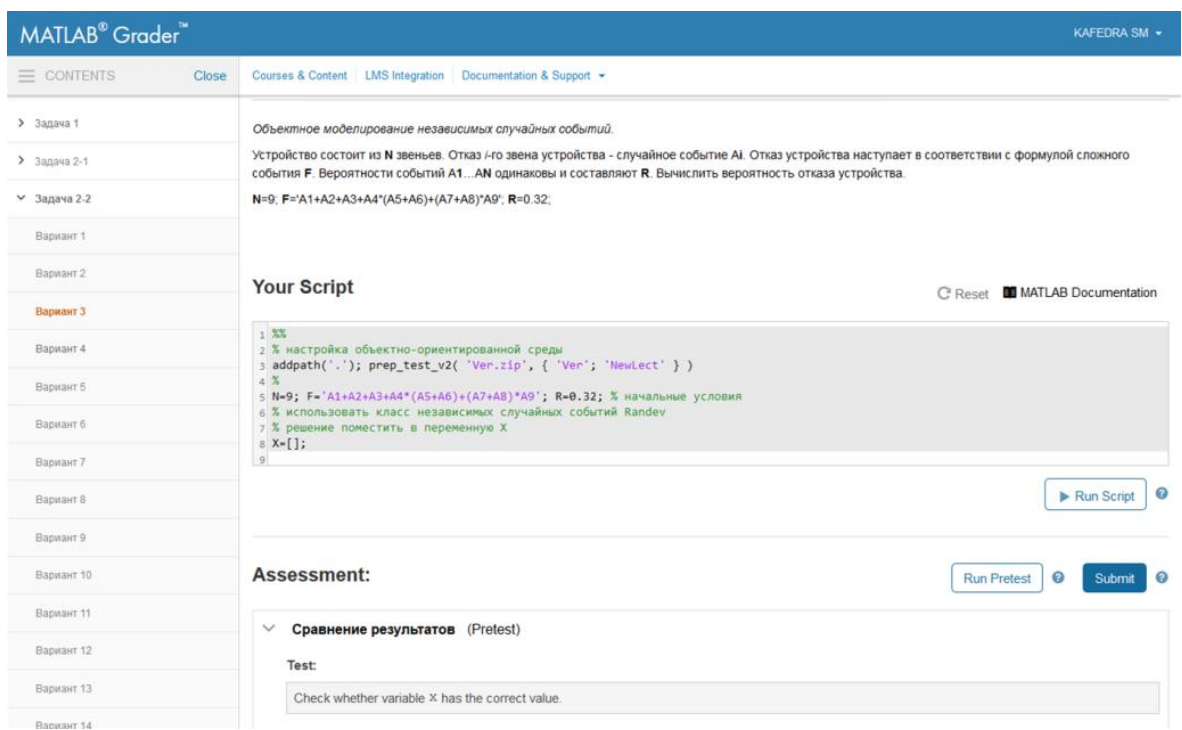

Fig. 4. The example of solving a problem using additional materials in the MATLAB Grader environment. 


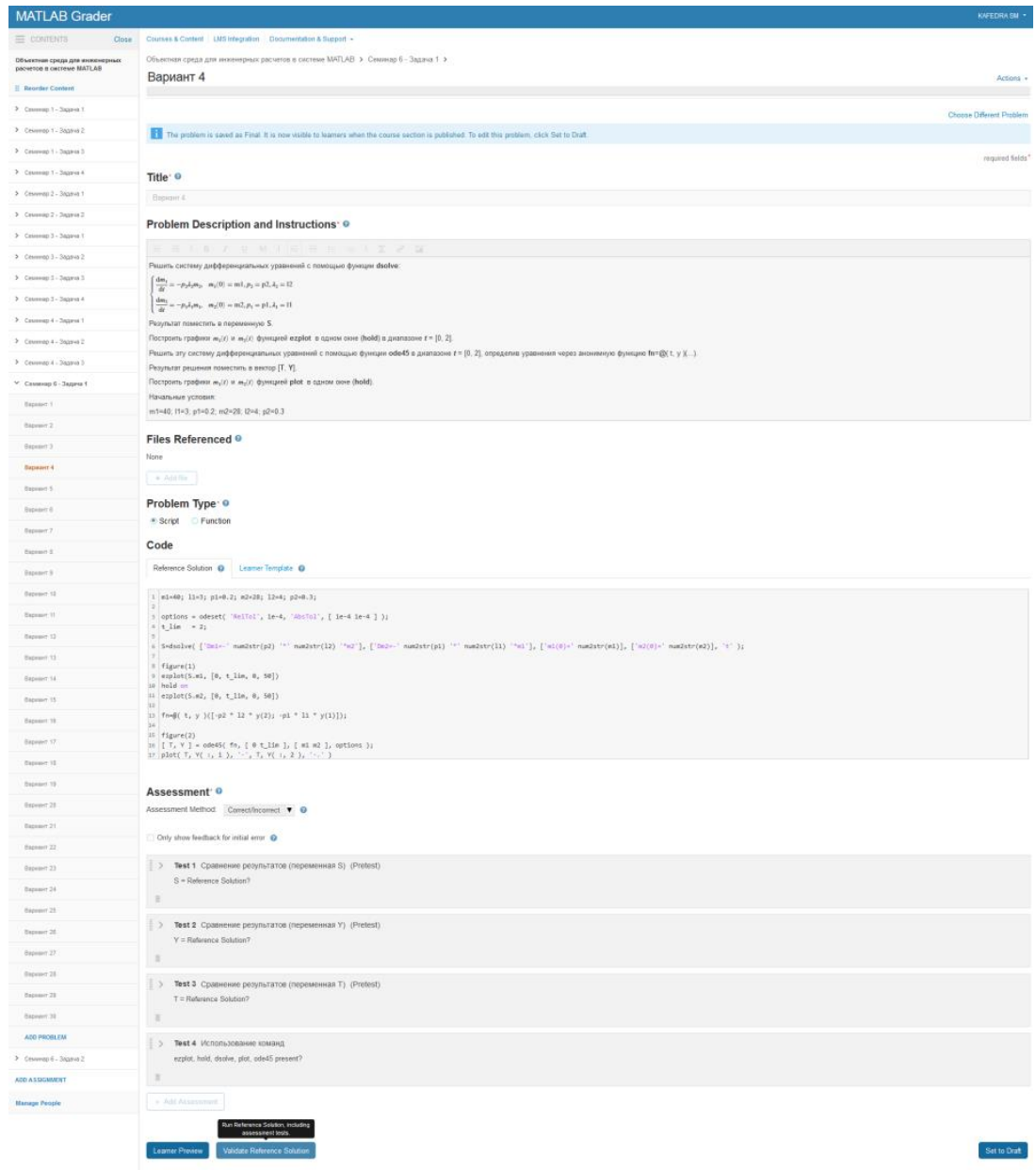

Output

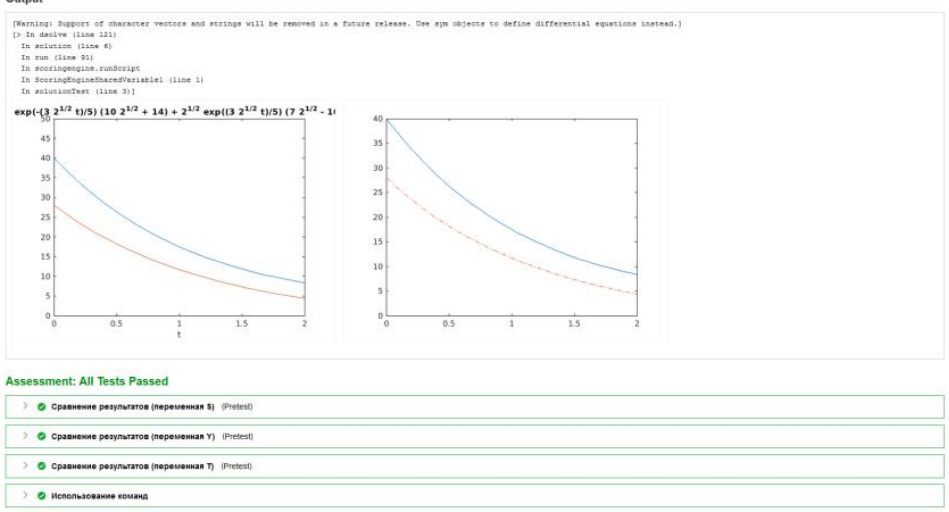

Fig. 5. The example of adding a problem and testing the benchmark solution. 


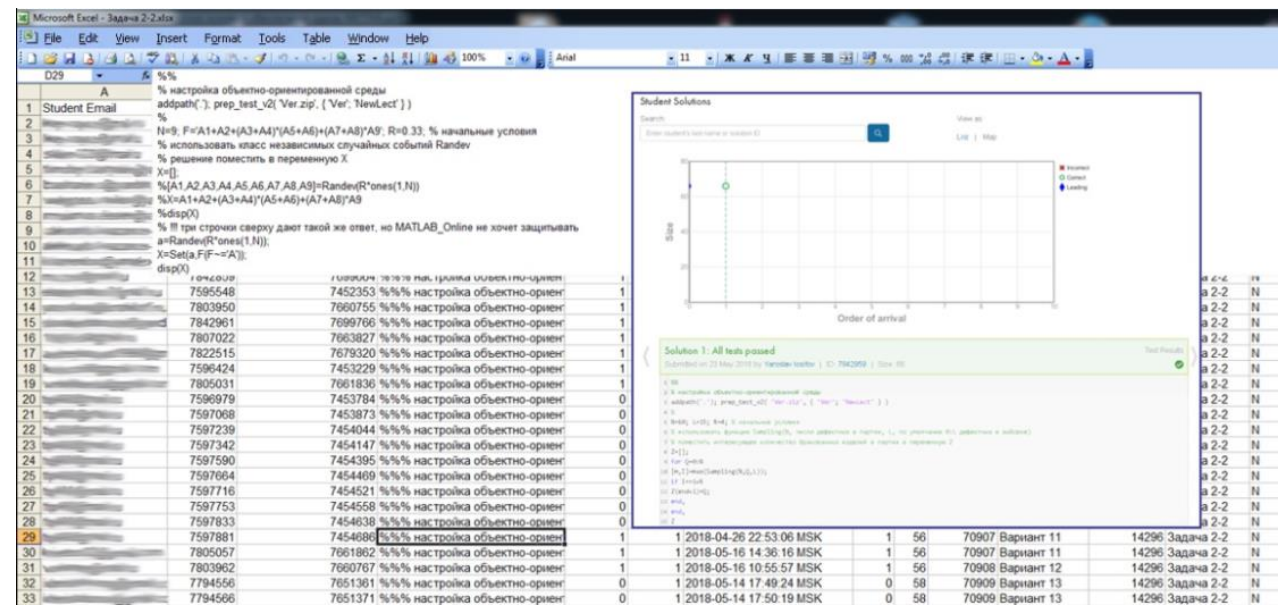

Fig. 6. Visual control of problem solving.

\section{Conclusion}

Using online technology for organizing practical sessions offers students additional tools for self-assessment, acquiring practical skills, preparing to classroom activities, reviewing of previously studied material. Perhaps, the so-called «inclusive technology» is the only possible way of getting information for people with limited access to real educational institutions. Unlike widely used «multiple choice tests» which are basically primitive tests with lists of different answers, using MATLAB Grader technology allows to perform a «creative» knowledge test. Well-considered use of object-oriented technology offers possibility to expand organization of practical sessions in the MATLAB Grader environment to wide variety of courses including humanities. All online tasks have a fundamental drawback which is impossible to rectify in modern conditions. It is impossible to perform a certified remote knowledge assessment of students. Possible solution for this problem is envisaged in a distant future.

\section{References}

1. V.V. Selivanov, S.V. Fedorov, Y.M. Nikolskaya \& S.V. Ladov, Research of the explosive formation of a compact element for meteoroids fragments and space debris modelling, Acta Astronautica (2019). DOI: 10.1016/j.actaastro.2019.03.005

2. Y.M. Nikolskaya, V.V. Selivanov, I.N. Omelchenko \& L.I. Rakhlina, Increase of the Methods of Program-target Planning of the Knowledge-intensive Sectors, 2018 Eleventh International Conference" Management of large-scale system development", MLSD, pp. 1-4, October 2018, IEEE (2018) DOI: 10.1109/MLSD.2018.8551855

3. A.V. Petyukov \& V.A. Pyr'yev, Propulsion performance and blast impulse of explosive charges in near-field explosion, Combustion, explosion, and shock waves, 55(4), pp. 471-477 (2019). DOI: 10.1134/S0010508219040142

4. I.F. Kobylkin \& I.A. Pavlova, Initiation of detonation in explosive charges by highspeed cone projectiles (Initsiirovaniye detonatsii v zaryadakh vzryvchatykh veshchestv vysokoskorostnymi udarnikami s konicheskoy golovnoy chastyu), Herald of the Bauman Moscow State Technical University. Series Mechanical Engineering, 6 (117) (2017). DOI: 10.18698/0236-3941-2017-3-54-65 
5. I.F. Kobylkin, A.V. Petyukov, I.A. Yakovenko, Detonation excitation in explosive charges confined by shells under high-speed impact of projectiles (Vozbuzhdeniye detonatsii $v$ zaryadakh vzryvchatogo veshchestva, ogranichennykh obolochkami, pri vysokoskorostnom vozdeystvii udarnikov), Engineering Journal: Science and Innovation 2015, № 3 (39) (2015). DOI: 10.18698/2308-6033-2015-3-1377

6. A.G. Rishnyak, S.A. Lyushnin, A.V. Petyukov, Interpretation of the results of numerical modelling in a system analysis of possible applications of basic research (Interpretatsiya rezultatov chislennogo modelirovaniya $v$ sistemnom analize vozmozhnykh primeneniy fundamentalnykh issledovaniy), Works of International Conference «XVII Khariton Topical Scientific Readings», Sarov: The Russian Federal Nuclear Center - All-Russian Scientific Research Institute of Experimental Physics (RFNC-VNIIEF), pp. 837-842 (2015)

7. V.M. Kupriyanov, A.G. Rishnyak, Technology for the integration of intelligent CAD ammunition "Engineer-M4" and universal computing and graphics packages (Tekhnologiya integratsii intellektual'noy SAPR boyepripasov "Inzhener-M4» $i$ universalnykh vychislitelnykh $i$ graficheskikh paketov), Military Enginery Scientific and Technical Journal, Counter-terrorism technical devices, Issue 16, № 7-8, pp. 44-48 (2012)

8. A.G. Rishnyak, System analysis of the effectiveness of weapons in the intellectual CAD "Engineer-M4" (Sistemnyy analiz effektivnosti oruzhiya $v$ intellektualnoy SAPR "Inzhener-M4»), Military Enginery Scientific and Technical Journal, Counterterrorism technical devices, Issue 16, № 9-10, pp. 63-68 (2012)

9. A.G. Rishnyak, Intelligent core of distributed engineering as the basis of modern engineering education technology (Intellektualnoye yadro raspredelennoy SAPR kak osnova sovremennoy tekhnologii inzhenernogo obrazovaniya), Engineering Journal: Science and Innovation, № 1(13) (2013). DOI: 10.18698/2308-6033-2013-1-579

10. A.G. Rishnyak \& S.A. Lyushnin, Object modelling and information support in the optimal design of weapons by the criterion of combat effectiveness (Obektnoye modelirovaniye $i$ informatsionnoye obespecheniye $v$ optimal'nom proyektirovanii sredstv porazheniya po kriteriyu boyevoy effektivnosti), Proceedings of the Russian Academy of Missile and Artillery Sciences, (3), pp. 44-51 (2017)

11. A.V. Babkin, V.A. Veldanov, E.F. Griaznov and others, Ammunition (Boyepripasy), Vol. 1, 3rd edition, corrected, Moscow, Bauman Moscow State Technical University Publishing House, p. 512 (2019)

12. A.V. Babkin, V.A. Veldanov, E.F. Griaznov and others, Ammunition (Boyepripasy), Vol. 2, Moscow, Bauman Moscow State Technical University Publishing House, p. 551 (2016)

13. Yu.M. Astapov, V.A. Veldanov, S.A. Lyushnin, Guidance systems and precisionguided munitions (Sistemy navedeniya i upravleniya vysokotochnykh boyepripasov), Moscow, Bauman Moscow State Technical University Publishing House, p. 172 (2019)

14. Yu.M. Astapov, S.A. Lyushnin, Guidance systems and precision-guided munitions (Sistemy navedeniya i upravleniya vysokotochnykh boyepripasov), Moscow, Bauman Moscow State Technical University Publishing House, Electronic resource 1 CDROM, FGUP "Informregistr" №0321203874 (2012)

15. A.G. Rishnyak, A.F. Ovchinnikov, Probabilistic problems of the theory of effectiveness of action (Veroyatnostnyye zadachi teorii effektivnosti deystviya), Moscow, Bauman Moscow State Technical University Publishing House, p. 304 (2006) 
16. A.G. Rishnyak, S.A. Lyushnin, Object-oriented modelling of the reliability of complex systems (Obyektno-oriyentirovannoye modelirovaniye nadezhnosti slozhnykh sistem), XII All-Russian Congress on Fundamental Problems of Theoretical and Applied Mechanics: Proceedings in 4 volumes, Vol.3: Mechanics of a deformable solid body, Ufa: Printing and Publications Center of Bashkir State University, pp. 1354-1356 (2019) 